\title{
Effect of particle size of bronchodilator aerosols on lung distribution and pulmonary function in patients with chronic asthma
}

\author{
D M MitChELL, M A SOLOMON, S E J TOLFREE, M SHORT, S G SPIRO \\ From University College Hospital, London
}

ABSTRACT The particle size of bronchodilator aerosols may be important in determining the site of deposition in the lung and their therapeutic effect. The distribution of aerosols (labelled with technetium-99m diethylene triamine pentacetic acid) of two different particle sizes has been studied by gamma camera imaging. The particles had mass median aerodynamic diameters (geometric standard deviations) of $1.4(1.4)$ and $5 \cdot 5(2.3) \mu \mathrm{m}$, and they were administered from a jet nebuliser to eight patients with chronic severe stable asthma. There was no significant difference in peripheral lung deposition with the two aerosols in any patient. The bronchodilator effect of the two aerosols was determined from cumulative dose-response studies. To avoid large doses that might mask possible differences in effect due to aerosol size, small, precisely determined incremental amounts of salbutamol (25-250 $\mu \mathrm{g}$ total lung dose) were used. The two doses were given via a nebuliser on separate occasions and the bronchodilator response was measured from $F_{E V}$, forced vital capacity, and peak expiratory flow 30 minutes after each dose. Bronchodilatation was similar with the two aerosols at each dose of salbutamol. There was therefore no difference in distribution within the lung or any difference in bronchodilator effect between an aerosol of small $(1.4 \mu \mathrm{m})$ particle size and an aerosol of $5.5 \mu \mathrm{m}$ in patients with severe but stable asthma.

Inhaled aerosols generated from jet nebulisers have an established place in the treatment of asthma. Previous studies have shown that aerosol deposition in the lung is dependent on particle size. ${ }^{1}$ The optimal size for $\beta$ adrenergic bronchodilator aerosols is said to be $2-5 \mu \mathrm{m}^{2}$ as particles of over $8 \mu \mathrm{m}$ become impacted in the upper airways and particles of $0.5 \mu \mathrm{m}$ or less penetrate the lungs but are too small to become deposited by sedimentation and so are largely exhaled. ${ }^{3}$ Tracheobronchial deposition is predominant when particles are 6-10 $\mu \mathrm{m}$ and alveolar deposition when particles are 3-4 $\mu \mathrm{m} .{ }^{4}$ The size distribution of aerosol particles is determined by the type of jet nebuliser and the flow rate of gas used to power it. Higher gas flow rates generate smaller particles. ${ }^{5}$ There is greater total lung deposition with particles of $1.8 \mu \mathrm{m}$ than with those of $4.6 \mu \mathrm{m}$ or $10.3 \mu \mathrm{m}$. $^{6}$ Particle size might therefore be important in affecting the

Address for reprint requests: Dr DM Mitchell, St Mary's Hospital, London W2 INY.

Accepted 16 December 1986 efficacy of therapeutic bronchodilator aerosols. Previous studies, ${ }^{78}$ however, and our own preliminary work have shown that the clinical response to adrenergic bronchodilators was not affected by particle size in the range $4-11 \mu \mathrm{m}$ in patients with chronic stable asthma. In these studies relatively high doses of bronchodilator were given, so the comparisons may have been made beyond the steep part of the doseresponse curve, masking potential benefits of different patterns of particle deposition. In a recent study ${ }^{9}$ small particle terbutaline aerosols $(1.8 \mu \mathrm{m})$ produced slightly greater bronchodilatation than large particle aerosols $(4.6$ and $10.3 \mu \mathrm{m})$ in patients with mild asthma. This led to the suggestion that with increasing airflow obstruction small particle aerosols were therapeutically more efficacious. It has, however, been shown that when airflow obstruction is present total lung deposition is generally increased. ${ }^{10}$

In an attempt to clarify some of these issues, we have studied several variables influencing aerosol deposition within the lung. Firstly, we have compared a typical therapeutic bronchodilator aerosol with a particle size of $5.5 \mu \mathrm{m}$ mass median aerodynamic diameter (MMAD) with a very small $(1.4 \mu \mathrm{m}$ 
MMAD) aerosol, in terms of both regional lung deposition (using gamma camera imaging) and change in lung function. Secondly, we delivered small doses of salbutamol to the lung to enable us to measure cumulative dose-response relationships. We studied patients with a history of severe asthma so that we could determine the effect of particle size in the presence of bronchoconstriction.

\section{Methods}

PATIENTS

Eight patients (four of them male; mean age 50 years) with well documented asthma were studied while clinically stable. All had a history of longstanding asthma with multiple hospital admissions. Two had required assisted mechanical ventilation during acute episodes and all had required intermittent oral high dose corticosteroids. All patients were taking regular corticosteroid drugs via a metered dose inhaler and three were also taking oral corticosteroids at the time of the study. All patients were receiving nebulised bronchodilators regularly. The patients stopped bronchodilator drugs at least 10 hours before each study and were studied at the same time of day, starting at $9 \mathrm{am}$. Approval for the study was obtained from the local ethical committee and each patient gave informed consent.

\section{DETERMINATION OF PARTICLE DISTRIBUTION} WITHIN THE LUNGS

Each patient inhaled a fixed dose of two different saline aerosols labelled with technetium-99m diethylene triamine pentacetic acid $\left({ }^{99 \mathrm{~m}} \mathrm{Tc}\right.$ DTPA). These aerosols, with two different particle size ranges, were inhaled on two separate days (not more than seven days apart) under constant conditions, so that distribution within the lung could be compared. After inhalation of the radiolabelled aerosol its distribution within the lung was determined by gamma camera imaging. On the first day an Acorn jet nebuliser (Medic-aid) was charged with $500 \mathrm{MBq}{ }^{99 m}$ Tc DTPA in $4 \mathrm{ml}$ of saline. Each patient wore a noseclip and inhaled from the nebuliser via a mouthpiece and two way valve for four minutes. Expiratory gas passed through a pneumotachograph (Fleisch) connected to a chart recorder, and was collected in a Douglas bag. A metronome was used to help patients to breathe at a constant rate. Expiratory tidal volume, respiratory rate, and minute ventilation were recorded and controlled on each run to ensure constant conditions. The outflow from the nebuliser incorporated a mechanical separator (Cis-optimist) ${ }^{11}$ to remove large particles and the driving flow rate was $101 \mathrm{~min}^{-1}$. The mass median aerodynamic diameter (MMAD) of the aerosol was 1.4 (geometric mean SD 1.4) $\mu \mathrm{m}$. On the sec- ond study day the inhalation procedure was identical but the separator was removed and a flow rate of 50 $1 / \mathrm{min}^{-1}$ was used. The aerosol generated had ano MMAD of $5.5(2 \cdot 3) \mu \mathrm{m}$. Preliminary studies showed흠 that a smaller dose (40\% average) of ${ }^{99} \mathrm{~m}$ Tc DTPA $\frac{\bar{\rho}}{\triangle}$ was delivered to the lung when the lower flow rate was $ळ$ used without the mechanical separator. A higher con- $₫$ centration of isotope was used on the second visit to $\rightarrow$ compensate for this and to allow delivery of similar ${ }_{-}^{\circ}$ radio activity to the lung and equal information den- $\vec{\omega}$ sity in the gamma camera images. The activity deposited in the lungs was about $40 \mathrm{MBq}$ on both study $\vec{x}$ days. On both days inhalation was followed rapidly by planar imaging of the lungs from posterior and os anterior projections, a Siemens 37 ZLC gamma cam- $\vec{c}$ era being used. Imaging took place with the patient supine, to a time limit of 180 seconds. The data were $\frac{}{2}$ analysed immediately by delineating the lungs and obtaining a geometric mean of total lung counts. This value was corrected for background counts and, from $\widehat{\nabla}$ knowledge of the gamma camera system response and $\vec{\bullet}$ attenuation due to the patient's chest thickness, the quantity of ${ }^{99 \mathrm{~m}} \mathrm{Tc}$ within the patient's lungs was calculated. This value was corrected for decay and expressed as a percentage of the total activity initially present in the nebuliser. From this the mass of salbutamol required in the nebuliser to deposit $25 \mu \mathrm{g} \stackrel{\circ}{\varnothing}$ and subsequent doses in the lungs was calculated. The distribution of isotope within lung regions was deter-음 mined by delineating the central third and peripheral two thirds of the lung and expressing the counts in the peripheral areas as a percentage of the total.

\section{SALBUTAMOL DOSE-RESPONSE STUDIES}

Immediately after lung imaging, we obtained baseline measurements of peak expiratory flow (PEF) FEV $\frac{1}{3}$ and forced vital capacity (FVC), the best of three readings of each measurement being recorded. Each 3 patient then inhaled increasing total lung doses of sal- -0 butamol. Four doses $(25,50,75$, and $100 \mu \mathrm{g})$ were delivered sequentially from the same nebuliser and apparatus and in exactly the same manner as in the determination of radioaerosol distribution within the $N$ lung. This was done to ensure accurate deposition of 0 known doses of salbutamol within the lung. Spi-N rometry was repeated 30 minutes after each dose to ${ }_{\sigma}^{\omega}$ determine a cumulative dose-response curve. The bronchodilator effects of the two different aerosol? particle sizes were then compared. All eight patientso finished the study.

DETERMINATION OF PARTICLE SIZE

On both study days the particle size distribution of the aerosols was determined with a seven stage cas-음 cade impactor (290 Marple Personal Cascade $\bar{\gamma}$ Impactor, Andersen Samplers Inc). On the first study응 
Table 1 Mean particle size distribution and ranges between individual patients of the small particle (mass median aerodynamic diameter 1.4 (geometric $S D$ 1.4) $\mu \mathrm{m}$ ) and large particle (MMAD 5.5 (2.3) $\mathrm{Hm}$ ) aerosols

\begin{tabular}{|c|c|c|}
\hline \multirow{2}{*}{$\begin{array}{l}\text { MMAD ( } \mu m) \\
\text { of particles }\end{array}$} & \multicolumn{2}{|c|}{$\begin{array}{l}\% \text { activity of total within each size range } \\
(\text { mean (range) })\end{array}$} \\
\hline & Small particles & Large particles \\
\hline $\begin{aligned} & \leqslant 0.5 \\
& 0.6-1 \cdot 0 \\
& 1 \cdot 1-2 \cdot 0 \\
& 2 \cdot 1-3 \cdot 5 \\
& 3 \cdot 6-6.0 \\
& 6 \cdot 1-10 \cdot 0 \\
& 10 \cdot 1-15 \cdot 0 \\
& 15 \cdot 1-21 \cdot 0 \\
&> 21\end{aligned}$ & $\begin{aligned} & 0.7(0-2.0) \\
& 18.4(11-25) \\
& 68.3(63-73) \\
& 4.7(1.3-9.0) \\
& 1.8(0-3.3) \\
& 1.4(0-2.4) \\
& 1.6(0-2.9) \\
& 1.2(0-2.2) \\
& 1.1(0-1.8) \\
& 100\end{aligned}$ & $\begin{array}{cl}0 & (0) \\
3 \cdot 8 & (0 \cdot 1-10) \\
9 \cdot 2 & (2 \cdot 9-15) \\
18 \cdot 1(17-19) \\
22.8(17-32) \\
21 \cdot 0(18-27) \\
15 \cdot 0(9 \cdot 7-18) \\
6.8(2 \cdot 5-10) \\
3 \cdot 2(0.8-7 \cdot 6) \\
100\end{array}$ \\
\hline
\end{tabular}

Table 2 Percentages of total dose of aerosol labelled with technetium-99m diethylene triamine pentacetic acid deposited in the peripheral two thirds of the lung fields for small (MMAD $1.4 \mu \mathrm{m})$ and large $(5.5 \mu \mathrm{m})$ particles

\begin{tabular}{llll}
\hline Subject no & $\begin{array}{l}\text { \% for small } \\
\text { particles }\end{array}$ & $\begin{array}{l}\text { \% for large } \\
\text { particles }\end{array}$ & $\begin{array}{l}\text { Difference } \\
\text { (small-large) }\end{array}$ \\
\hline 1 & 62 & 64 & -2 \\
2 & 63 & 63 & 0 \\
3 & 60 & 57 & +3 \\
4 & 63 & 63 & 0 \\
5 & 55 & ND & ND \\
6 & 57 & 55 & +2 \\
7 & 67 & 63 & +4 \\
8 & 57 & 58 & -1 \\
\hline
\end{tabular}

ND, not done.

day the patient inhaled small aerosol particles (MMAD $1.4 \mu \mathrm{m}$ ) potentially capable of deep lung penetration. Ninety four percent of this nebulised solution was in the form of particles with a diameter of less than $6 \mu \mathrm{m}$ (table 1). On the second day larger particles were inhaled (MMAD $5.5 \mu \mathrm{m}$ ), only $54 \%$ having a diameter of less than $6 \mu \mathrm{m}$. The presence of salbutamol or DTPA in the saline aerosol made no difference to the size characteristics of the particles. ${ }^{99 m}$ Tc DTPA leaks through lung epithelium to the bloodstream with a half time of about $\mathbf{4 0}$ minutes in non-smokers, and it is then excreted in the kidney. Subjects drank plenty of fluid to enhance clearance of isotope and minimise absorbed radiation dose. Paired Student's $t$ tests were used for statistical analysis.

\section{Results}

Peripheral deposition with the smaller nebulised particles was not significantly greater than with larger particles (table 2). The mean peripheral deposition for the eight patients was $60.5 \%$ for small particles and $60.4 \%$ for large particles.

Table 3 shows the baseline $\mathrm{FEV}_{1}$ for each patient, expressed as a percentage of predicted $\mathrm{FEV}_{1}$; the percentage difference in baseline measurements for each patient between the two study days; and the percentage improvement in $\mathrm{FEV}_{1}$ for each patient after deposition of $25 \mu \mathrm{g}$ and $250 \mu \mathrm{g}$ salbutamol for the two aerosol sizes. Three of the patients had considerable obstruction ( $\left.\mathrm{FEV}_{1}<30 \%\right)$ at the beginning of the

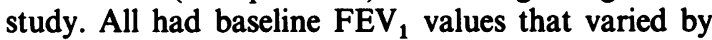
$13 \%$ or less between the two study days except for patient 4 , who varied by $23 \%$. Figure 1 shows the mean increase in $\mathrm{FEV}_{1}$ for the eight patients after inhalation of each dose of salbutamol contained in small and large particles. There was no consistent difference between the effects of small and of large particles in changing $\mathrm{FEV}_{\mathbf{1}}$.

Table $3 F E V_{1}$ baseline values and percentage improvement in FEV after deposition of 25 and $250 \mu g$ salbutamol within the lung

\begin{tabular}{|c|c|c|c|c|c|c|c|c|c|}
\hline Subject No: & 1 & 2 & 3 & 4 & 5 & 6 & 7 & 8 & Mean \\
\hline \multirow{4}{*}{$\begin{array}{l}\text { FEV }_{1} \text { (\% predicted) } \\
\text { baseline on first study day } \\
\text { FEV baseline on first } \\
\text { (small particle) study day } \\
\text { FEV, baseline on second } \\
\text { (large particle) study day } \\
\% \text { differences in baseline } \\
\text { between small particle day } \\
\text { and large particle day } \\
\% \text { improvement in FEV }\end{array}$} & 23 & 52 & 68 & 27 & 53 & 46 & 25 & 83 & 47 \\
\hline & 0.55 & 2.05 & $1 \cdot 2$ & $1 \cdot 1$ & $2 \cdot 0$ & 0.9 & 0.75 & $2 \cdot 45$ & 1.37 \\
\hline & 0.6 & $2 \cdot 1$ & $1 \cdot 15$ & 0.85 & $2 \cdot 25$ & 0.8 & 0.85 & $2 \cdot 3$ & 1.36 \\
\hline & $+8 \%$ & $+2 \%$ & $-4 \%$ & $-23 \%$ & $+13 \%$ & $-11 \%$ & $+13 \%$ & $-6 \%$ & $-1 \%$ \\
\hline $\begin{array}{l}\text { Small particles } \\
\text { Large particles } \\
\% \text { improvement in } \mathrm{FEV}\end{array}$ & $\begin{array}{l}39 \\
14\end{array}$ & $\begin{array}{r}7 \\
22\end{array}$ & $\begin{array}{r}14 \\
0\end{array}$ & $\begin{array}{r}8 \\
27\end{array}$ & $\begin{array}{l}20 \\
21\end{array}$ & $\begin{array}{l}0 \\
0\end{array}$ & $\begin{array}{r}12 \\
0\end{array}$ & $\begin{array}{l}14 \\
13\end{array}$ & $\begin{array}{l}14 \\
12\end{array}$ \\
\hline $\begin{array}{l}\text { Small particles } \\
\text { Large particles }\end{array}$ & $\begin{array}{l}61 \\
45\end{array}$ & $\begin{array}{l}21 \\
28\end{array}$ & $\begin{array}{l}38 \\
30\end{array}$ & $\begin{array}{l}12 \\
29\end{array}$ & $\begin{array}{l}34 \\
26\end{array}$ & $\begin{array}{l}22 \\
30\end{array}$ & $\begin{array}{l}42 \\
26\end{array}$ & $\begin{array}{l}23 \\
23\end{array}$ & $\begin{array}{l}32 \\
30\end{array}$ \\
\hline
\end{tabular}




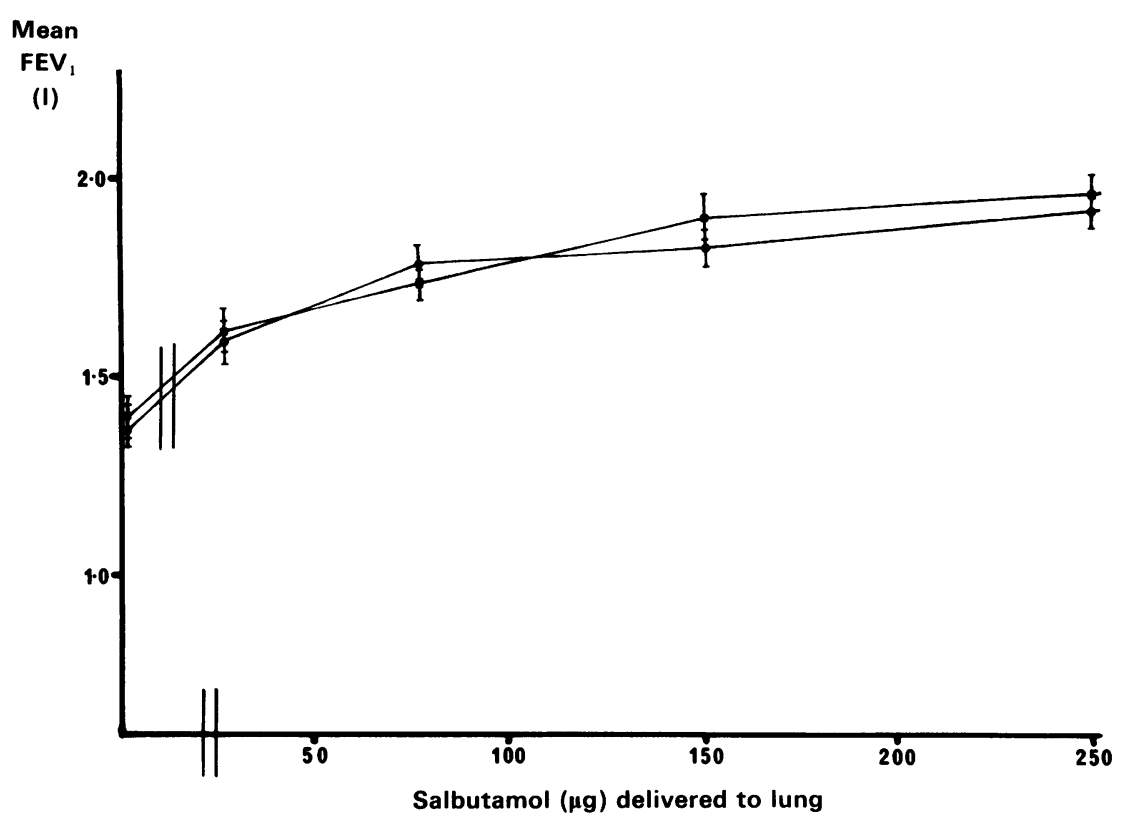

Cumulative salbutamol dose-response curves obtained with small (1.4 $\mu \mathrm{m}-\square)$ and large (5.5 $\mu \mathrm{m}-\mathrm{O})$ particles.

\section{Discussion}

In this study we compared the deposition pattern within the lung and the bronchodilator effects of a very small aerosol $(1.4 \mu \mathrm{m})$ with an aerosol produced by a standard clinical jet nebuliser run at a gas flow rate of $51^{-1} \min (5 \cdot 5 \mu \mathrm{m})$. By using techniques to deposit very small known quantities of bronchodilator accurately in the lung we were able to compare the bronchodilator effects of the two aerosols at very low doses.

It has been suggested that, in the presence of airflow obstruction, small particle aerosols might penetrate more deeply into the lungs and therefore cause more bronchodilatation than large particle aerosols. As we were interested in possible practical applications of any differences between the two particle sizes, we chose to study patients with severe chronic asthma, where the appreciable airflow obstruction may be important in determining deposition and effect.

The deposition patterns of the two aerosols $(1.4$ and $5.5 \mu \mathrm{m}$ ) were almost identical in all eight subjects, including those with more severe airflow obstruction. Roughly $60 \%$ of the aerosol deposited in the lung was deposited in the lung periphery with both sizes of aerosol. This finding argues against the view that small particle aerosols achieve greater lung penetration in the presence of airflow obstruction.

Recent studies in patients with stable chronic asthma have showed no difference in bronchodilato effect when salbutamol has been delivered via a je? nebuliser driven at 4 and at $81 \mathrm{~min}^{-1} .^{78}$ The highp doses of salbutamol, however, may have masked differences in effects due to particle size. By calcu官 lating the dose of radiolabel deposited in the lung just before each dose-response study was performed, we्ठ could deliver precise small amounts of salbutamol to the lungs and so determine whether small particle aerosols gave additional bronchodilatation. Such $\underset{\mathrm{B}}{\mathrm{B}}$ difference, if present, might be important in treating. severe acute asthma when considerable airflows obstruction is present. No consistent differences between small and large particle deposition were seen however, even with low doses of salbutamol. The practical implication of these findings is that differences in particle size within the range 1.4-5.5 $\mu$ no for aerosols delivered from standard jet nebulisers are not critical for bronchodilatation in patients withu moderate or severe asthma. Although particle sizE may be a major determinant of lung deposition if normal airways, abnormal airway geometry is likel to be a further determining factor in patients wit asthma.

\section{References}

1 Brain JD, Valberg PA. State of the art. Deposition of aerosols in the respiratory tract. Am Rev Respir Dis 1979;120:1325-73. 
2 Rees PJ, Clark TJH. The importance of particle size in response to inhaled bronchodilators. Eur J Respir Dis 1982;63, suppl 119:73-8.

3 Swift DL. Generation and respiratory deposition of therapeutic aerosols. Am Rev Respir Dis 1980;122:71-7.

4 Stahlhofen W, Gebhart J, Heyder J. Experimental determination of the regional deposition of aerosol particles in the human respiratory tract. Am Ind Hyg Ass J 1980;41:385-98.

5 Clay MM, Pavia D, Newman SP, Clarke SW. Factors influencing the size distribution of aerosols from jet nebulisers. Thorax 1983;38:755-9.

6 Clay M, Pavia D, Clark S. Nebulised aerosols [abstract]. Thorax 1986;41:248.

7 Douglas JG, Leslie MJ. Crompton GK, Grant IWB. A comparative study of two doses of salbutamol nebuliser at 4 and $8 \mathrm{l} / \mathrm{min}$ in patients with chronic asthma. Br J Dis Chest 1986;80:55-8.

8 Hadfield JW, Wildebank WJ, Bateman JRM. Is driving gas flow rate clinically important for nebuliser therapy? Br J Dis Chest 1986;80:50-4.

9 Clay MM, Pavia D, Clark SW. Effect of aerosol particle size on bronchodilatation with nebulised terbutaline in asthmatic subjects. Thorax 1986;41:364-8.

10 Chan TL, Lippman M. Experimental measurement and empirical modelling of the regional deposition of inhaled particles in humans. Am Ind Hyg Ass J 1980;41:399-409.

11 Jones JG, Minty BD, Royston D. The physiology of leaky lungs. Br J Anaesthiol 1982;54:705-21. 